\title{
APRENDIZADOS E CUIDADOS DE MÃES NO MÉTODO CANGURU
}

\author{
MOTHERS' LEARNING AND CARE \\ IN THE KANGAROO METHOD
}

\section{APRENDIZAJE Y CUIDADO DE LAS MADRES EN EL MÉTODO CANGURO}

\author{
Joise Magarão Queiroz Silva ${ }^{1}$ \\ Mariza Silva Almeida ${ }^{2}$ \\ Edméia de Almeida Cardoso Coelho ${ }^{3}$ \\ Karla Ferraz dos Anjos ${ }^{4}$ \\ Tyciana Paolilo Borges 5 \\ Írbia Fernandes de Medeiros
}

Como citar este artigo: Silva JMQ, Almeida MS, Coelho EAC, Anjos KF, Borges TP, Medeiros ÍF. Aprendizados e cuidados de mães no Método Canguru. Rev baiana enferm. 2020;34:e36994.

Objetivo: analisar o significado da vivência de mães no Método Canguru. Método: estudo exploratório e descritivo, com abordagem qualitativa, realizado em duas instituições públicas no município de Salvador, Bahia, Brasil. A produção empírica dos dados deu-se por meio da observação participante, entrevista semiestruturada e oficinas de reflexão, com a participação de 19 mães de recém-nascidos. Para operacionalizar os dados, utilizou-se a análise de conteúdo temática categorial. Resultados: a vivência de mães na enfermaria do Método Canguru possibilitou a construção de conhecimentos atrelada à ampliação e/ou aquisição de experiências, principalmente para as primíparas, por se tratar de recém-nascido prematuro, que necessita de cuidado singular e diferenciado, somado ao aumento do vínculo entre mãe/recém-nascido com os demais familiares e profissionais de saúde. Conclusão: a vivência de mães na enfermaria do Método Canguru favoreceu aprendizado significativo para elas cuidarem com mais segurança de seus filhos no domicílio, após a alta hospitalar.

Descritores: Mães. Recém-Nascido. Método Canguru. Enfermagem. Aprendizagem.

Objective: to analyze the meaning of the experience of mothers in the Kangaroo Method. Method: exploratory and descriptive study, with qualitative approach, conducted in two public institutions in the city of Salvador, Bahia, Brazil. The empirical production of the data was through participant observation, semi-structured interviews and reflection workshops, with the participation of 19 mothers of newborns. To operationalize the data, the categorical thematic content analysis was used. Results: the continuous experience of mothers in the Kangaroo Care ward enabled the construction of knowledge linked to the expansion and/or acquisition of experiences, especially for primiparous women, for being premature newborns, who need singular and differentiated care, added to the increased bond between mother/newborn with other family members and health professionals. Conclusion: the experience of mothers

\footnotetext{
Enfermeira. Universidade Federal da Bahia. Docente da União Metropolitana de Educação e Cultura. Salvador, Bahia, Brasil. josita_I I4@hotmail.com. http://orcid. org/0000-0002-5।42-II50

Enfermeira. Doutora em Enfermagem. Docente da Universidade Federal da Bahia. Salvador, Bahia, Brasil. http://orcid.org/0000-000 I-78I6-453X

Enfermeira. Doutora em enfermagem. Docente da Universidade Federal da Bahia. Salvador, Bahia, Brasil. http://orcid.org/0000-000 I-67। 8-4922.

Enfermeira. Doutora em Enfermagem. Docente da União Metropolitana de Educação e Cultura. Salvador, Bahia, Brasil. http://orcid.org/0000-0002-5453-8303.

Enfermeira. Mestre em Enfermagem. Docente da União Metropolitana de Educação e Cultura. Salvador, Bahia, Brasil. http://orcid.org/0000-0003- 7 784-6937.

Enfermeira. Especialista em enfermagem obstétrica. Pesquisadora independente. Salvador, Bahia, Brasil. http://orcid.org/0000-0002-92 17-6577.
} 
in the Kangaroo Care ward favored significant learning for them to care more safely for their children at home after hospital discharge.

Descriptors: Mothers. Infant, Newborn. Kangaroo-Mother Care Method. Nursing. Learning.

Objetivo: analizar el significado de la experiencia de las madres en el Método Canguro. Método: estudio exploratorio y descriptivo, con enfoque cualitativo, realizado en dos instituciones públicas de la ciudad de Salvador, Babía, Brasil. La producción empírica de los datos fue a través de la observación participante, entrevistas semiestructuradas y talleres de reflexión, con la participación de 19 madres de recién nacidos. Para recoger los datos, se utilizó el análisis del contenido temático de la categoría. Resultados: la experiencia de las madres en la enfermaría de Método Canguro permitió la construcción de conocimientos vinculados a la expansión y/o adquisición de experiencias, especialmente para mujeres primíparas, porque son recién nacidos prematuros, que necesitan atención singular y diferenciada, sumado al mayor vínculo entre madre/recién nacida con otros miembros de la familia y profesionales de la salud. Conclusión: la experiencia de las madres en la enfermaría del método canguro favoreció un aprendizaje significativo para que cuidaran con más seguridad a sus hijos en casa después del alta hospitalaria.

Descriptores: Madres. Recién Nacido. Método Madre-Canguro. Enfermería. Aprendizaje.

\section{Introdução}

Para uma mulher, o nascimento de um filho geralmente significa mudanças em suas atribuições como esposa e mãe. Entretanto, o nascimento de um recém-nascido (RN) prematuro é uma experiência nova para a genitora, quando é mãe pela primeira vez ou já tenha outros filhos, e pode gerar uma crise para toda a família ${ }^{(1)}$.

O número elevado de nascimentos prematuros e de baixo peso e a necessidade de suporte a ser ofertado pelos profissionais de saúde conduziu o Ministério da Saúde (MS) a apoiar e padronizar ações nas unidades neonatais, lançando, em 2000, a Norma de Atenção Humanizada ao Recém-Nascido de Baixo Peso. Além dessa norma, tem relevância o Método Canguru (MC), que visa contribuir para mudanças na postura profissional, com vista à humanização da assistência ao $\mathrm{RN}^{(2)}$.

A visão brasileira sobre o Método Canguru, idealizado na Colômbia, em 1979, constituiu mudança do paradigma da atenção perinatal e associação entre humanização e avanços tecnológicos. Na sua operacionalização, esse método começa numa fase prévia ao nascimento do $\mathrm{RN}$ pré-termo e/ou de baixo peso, com a identificação precoce das gestantes de risco. Sua ação consiste em manter o RN de baixo peso em contato pele a pele, na posição vertical, junto ao tórax da mãe, do pai ou de outro familiar, de maneira orientada, segura e acompanhada de suporte assistencial de uma equipe de saúde adequadamente treinada ${ }^{(3)}$.

Dirigido exclusivamente para gestantes em situações clínicas ou obstétricas de risco para nascimento de RN prematuro e/ou de baixo peso, esse método é recomendado desde o momento da admissão na Unidade Neonatal até a alta hospitalar. Após a alta, os recém-nascidos deverão ser acompanhados por equipe multiprofissional em ambulatório especializado ou na própria maternidade onde ficou internado e na atenção básica à saúde ${ }^{(2)}$.

Operacionalmente, o Método Canguru é aplicado em três etapas. A mudança de uma para outra vai depender do quadro clínico e do peso do RN. Na primeira etapa, tem destaque o acesso precoce e livre da mãe e/ou do pai à Unidade de Cuidados Intensivos Neonatal (UTIN) e Unidade de Cuidados Intermediários Neonatais Convencionais (UCINco), visando estimular a amamentação precoce e participação do pai e da mãe nos cuidados do $\mathrm{RN}$, com início do contato pele a pele, tão logo as condições clínicas permitam. Na segunda etapa, mãe e RN permanecem em enfermaria conjunta e a posição canguru deve ser incentivada pelo maior tempo possível. A terceira etapa refere-se à alta hospitalar, com 
acompanhamento ambulatorial até que o RN atinja o peso de 2.500 gramas $^{(4)}$.

Dentre as vantagens do Método Canguru destacam-se o aumento do vínculo com o RN, menor tempo de separação entre mãe-filho e evitação de longos períodos sem estimulação sensorial. Contribui também no estímulo ao aleitamento materno, o que favorece a frequência, a precocidade e a duração da mamada; possibilita desenvolver mais segurança, confiança e competência da mãe e/ou do pai no cuidado, mesmo após a alta hospitalar; melhor controle térmico; menor número de RN em unidades de cuidados intermediários, devido à maior rotatividade de leitos; melhor relacionamento da família com a equipe de saúde; diminuição da infecção relacionada à assistência à saúde; e menor permanência hospitalar ${ }^{(2)}$.

Além dessas vantagens do Método Canguru, nota-se a importância de o pai e a mãe receberem orientações dos profissionais da saúde, especialmente da equipe de enfermagem, sobre sua participação no cuidado do filho. Essa atuação colabora com o desenvolvimento biopsicossocial, proporcionando a formação e o fortalecimento do vínculo afetivo ao conjunto, RN, mãe, pai e família $^{(4)}$. Para as mães, este método devolve a autoestima, visto que se sentem indispensáveis no cuidado do RN, assim como ameniza possíveis mágoas relacionadas ao parto, devido à reaproximação com a criança ${ }^{(5)}$.

Ademais, entende-se que as ações/atividades que compõem esse método constituem estratégias essenciais para mudança institucional na busca da atenção à saúde centrada na humanização da assistência e no princípio da integralidade do cuidado, com o propósito de favorecer a promoção do cuidado ao $\mathrm{RN}$, servir como apoio à mãe, pai e famílias específicas.

As mães devem ser orientadas por uma equipe multiprofissional acerca da sua atuação no Método Canguru, como coparticipante no cuidado e na recuperação de seu filho ${ }^{(6)}$. Diante da efetiva contribuição que esse método oferece nas situações de prematuridade, com êxito institucionalmente comprovado para o desenvolvimento do RN, pressupõe-se que as mães reconhecem e vivenciam os ganhos no âmbito do cuidado e da relação mãe e filho.

Ao buscar publicações atuais referentes ao tema proposto na Biblioteca Virtual em Saúde (BVS), utilizando os descritores "mães", "cuidados", "Método Canguru" e "enfermagem", observou-se lacuna na produção científica sobre o aprendizado e o cuidado de mães no Método Canguru. Verificou-se escassez de publicações nacionais e internacionais referentes ao objeto de estudo, especialmente entre os anos de 2015 e 2018, o que justifica a ampliação de estudos com esta abordagem.

Assim, buscou-se responder à questão de pesquisa: Que significado tem para mães a sua vivência no Método Canguru? Para responder a esse questionamento, definiu-se como objetivo analisar o significado da vivência de mães no Método Canguru.

\section{Método}

Trata-se de estudo exploratório e descritivo com abordagem qualitativa desenvolvido em duas Instituições públicas com leitos obstétricos no município de Salvador, Bahia, Brasil, denominadas Instituição A e Instituição B.

A instituição A é um hospital geral de grande porte, de alta complexidade, terciário e de caráter assistencial e de ensino, certificado pelos Ministérios da Saúde e da Educação. É referência nos serviços de emergência, hemorragia digestiva, nefrologia, pediatria, clínica médica, cirurgia buco-maxilo-facial, cirurgia geral, neurocirurgia, cirurgia pediátrica e neonatal, maternidade de alto risco, entre outras especialidades médicas. A instituição B é uma maternidade escola da rede pública, a mais antiga construída do Brasil, inaugurada em outubro de 1910, pertencente ao governo Federal, referência para gravidez de risco. Foi credenciada como hospital amigo da criança em 1996 e possui o projeto mãe canguru desde 1997. É sede do primeiro banco de leite humano da região metropolitana de Salvador desde 2001.

Este artigo é parte da dissertação de mestrado Intitulada "Significado da Vivência de Mães no Método Canguru", que demonstra a relevância 
desse método na promoção da saúde de neonatos e na aprendizagem dos cuidados pela mãe. Verifica-se que, ao dar voz às mães, estas podem expressar não apenas seu reconhecimento ao alcance dos objetivos do método como também o significado da convivência na enfermaria canguru.

Participaram da pesquisa 19 mães, sendo 10 da Instituição A e 9 da Instituição B. Dentre as 10 participantes da Instituição A, 9 realizaram a entrevista e uma não a realizou, por ter tido alta no dia da coleta. O mesmo ocorreu na Instituição B. Das 9 mães participantes, apenas 7 realizaram a entrevista e 2 não a realizaram pelo mesmo motivo da Instituição A. Dessas 19 participantes, 18 tinham bebês prematuros e 1 de baixo peso ao nascer.

Para a seleção, adotaram-se os critérios de inclusão: ter idade mínima de 18 anos; estar em condições físicas e psicológicas para ser entrevistada e/ou participar das oficinas e ter no mínimo uma semana convivendo em uma enfermaria do Método Canguru de forma integral junto com seu RN. Os critérios de exclusão foram apresentar déficit cognitivo e mental, bem como a convivência na unidade canguru inferior a uma semana.

A fase de produção empírica dos dados ocorreu durante os meses de julho a dezembro de 2013 em três momentos, utilizando-se, em cada uma delas, a técnica específica de observação participante, entrevista semiestruturada e oficinas de reflexão. A observação, feita pela pesquisadora, ocorreu nos turnos matutino e vespertino, em ambas as instituições, conforme a disponibilidade da pesquisadora e das participantes, sendo registrada em diário de campo. Após cada visita, realizava-se o registro em local apropriado, externo à unidade, com rigor técnico, de modo a ter informações fidedignas, que retratassem as situações observadas com pertinência para o objeto de estudo. A observação foi a primeira etapa de coleta, para possibilitar a aproximação da pesquisadora com o campo e as mulheres. Essa observação continuou durante as demais etapas. Para a realização do estudo, primeiro foi feito um teste piloto, com o questionário semiestruturado, aplicado a três mulheres, com o propósito de servir para aperfeiçoamento do questionário semiestruturado.

No diário de campo, eram registrados: ações dos profissionais de saúde com as mães na enfermaria canguru; cuidados prestados pelas mães aos recém-nascidos; palestras e atividades educativas realizadas pelos profissionais na unidade; visitas recebidas pelas mães; aprendizado e prática dos cuidados tanto dos profissionais como das mães; e atuação dos demais familiares durante as visitas.

As oficinas de reflexão foram a segunda etapa da coleta. Aconteceram em dois encontros, no próprio espaço de cada unidade canguru (A, B), mediante acordo com a enfermeira coordenadora das unidades, que viabilizou a realização das oficinas no mesmo espaço da Unidade Canguru, com a participação livre das mães, que estariam mais tranquilas e despreocupadas, por permanecerem junto a seus filhos. Nas oficinas, as pesquisadoras contaram com o apoio de uma estudante de graduação e da orientadora. Cada oficina durou, em média, 2 horas.

As entrevistas com as mães foram realizadas pela pesquisadora em local reservado e gravadas, a fim de garantir a precisão dos depoimentos, com duração média de 15 minutos. A entrevista foi guiada por um formulário semiestruturado para obtenção dos dados de identificação, sociodemográficos e obstétricos das participantes, seguido da entrevista, norteada pela questão: "O que significa, para a senhora, estar aqui na unidade Mãe Canguru?"

Para manter o anonimato, as mães entrevistadas receberam uma codificação conforme sua participação em entrevistas e oficinas, respectivamente: Entrevistas - E1, E2...; e oficinas - OfA (Instituição A), OfB (Instituição B). Após o consentimento, as participantes assinaram o Termo de Consentimento Livre e Esclarecido (TCLE), levando em consideração os critérios da Resolução $n^{\circ} 466 / 2012$, do Conselho Nacional de Saúde, que diz respeito à pesquisa envolvendo seres humanos ${ }^{(7)}$. Para operacionalizar a análise e tratar as informações coletadas, resultantes da observação, das entrevistas e oficinas, optou-se 
por utilizar a análise de conteúdo, modalidade temática categorial norteada por Bardin ${ }^{(8)}$.

A técnica de análise seguiu os três polos cronológicos: pré-análise, após a organização do material e leitura com registro de detalhes; exploração do material e leituras sucessivas do material transcrito, para apreender temas que emergiam; e tratamento dos resultados ${ }^{(8)}$. Dessa forma, iniciou-se a análise com a leitura da transcrição de cada entrevista e das oficinas associadas aos registros do diário de campo resultantes das observações, para contato inicial, e seguiu-se com leituras exaustivas para conhecimento e apreensão das informações.

O projeto foi aprovado pelo Comitê de Ética em Pesquisa da Escola de Enfermagem da Universidade Federal da Bahia, sob Parecer no 309606 e Certificado de Apresentação de Apreciação Ética (CAAE) no 16367713.4.0000.5531. A pesquisa foi iniciada após apresentação, leitura e assinatura do TCLE pelas mães.

\section{Resultados}

Foram pesquisadas 19 mães, com idades entre 18 e 35 anos e média de 20 anos. No total de dias de internação na maternidade, a distribuição ficou heterogênea, entre 11 a 50 dias de internação. No quesito raça/cor, 12 autodeclararam a cor parda, 3 negras, 3 morenas e 1 amarela.

Ao fim da análise de conteúdo temática categorial dos dados das respostas das entrevistas e das oficinas de reflexão emergiram uma categoria e cinco subcategorias. Categoria 1: Significado, experiência, aprendizado e fortalecimento de vínculo mãe e RN prematuro no Método Canguru; Subcategoria 1: Significado do Método Canguru para mães de RN prematuro; Subcategoria 2: Experiência de mães de RN prematuro no Método Canguru; Subcategoria 3: Aprendizado de mães de RN prematuro com o Método Canguru; Subcategoria 4: Fortalecimento do vínculo mãe-filho no Método Canguru e; Subcategoria 5: Enfermaria canguru como local para a aprendizagem.

\section{Categoria 1: Significado, experiência, aprendizado e fortalecimento de vínculo mãe e RN prematuro no Método Canguru}

Esta categoria engloba cinco subcategorias que abordam o significado da experiência de mães em enfermaria Método Canguru e os possíveis benefícios para o cuidado ao $\mathrm{RN}$ prematuro com o aprendizado, assim como o fortalecimento de vínculos.

\section{Subcategoria 1: Significado do Método Canguru para mães de RN prematuro}

Nesta subcategoria, as mães entrevistadas relataram que o Método Canguru é significativo para o aprendizado e os cuidados do RN.

\begin{abstract}
Significa muita coisa, que eu aprendi bastante. Muita coisa que eu não sabia, já estou sabendo [...] (E3). Uma coisa boa, que eu posso pegar em minha filha, posso dar banho nela, posso dormir perto dela (E6). Significa que eu estou perto dele, a presença dele, sentir o cheiro dele (E13). Eu aprendo a cuidar do bebê [...] é prematuro, tem que ter um cuidado especial (E4). Aprender o modo certo de cuidar de minh a filha, por ela ser prematura um novo conbecimento, um modo de ensinar coisa nova [...] (E8). Eu aprendi tudo. Eu não tinha muita experiência, eu tinha medo de pegar e não pegava [...] Eu perdi o medo, dar banbo, eu só aprendi a dar banbo no $3^{\circ}$ banbo (OfA E5). É bom o aprendizado, pra gente conbecer mais o nosso filho, os sintomas que ele sente, como cólica. A gente aprende várias coisas, o banbozinho [...] dele aqui é diferente, é enroladinho, as medicações, como agir com o bebê prematuro, como lidar [...] com o bebê prematuro, os riscos [...] que eu não sabia, que é meu primeiro filho. Pra mim só isso. (E11).
\end{abstract}

Subcategoria 2: Experiência de mães de RN prematuro no Método Canguru

Nesta subcategoria, evidenciou-se que a experiência de mães no Método Canguru é inovadora e possibilitou aprendizado do cuidado do $\mathrm{RN}$ prematuro, que tem suas particularidades e necessitam ser consideradas. Esse preparo é essencial para a continuidade do cuidado no domicílio.

Para mim é uma experiência nova, é uma experiência, assim, vamos dizer, que você está mais perto, você aprende coisas novas, dá nova oportunidade de você conbecer o que é o bebê prematuro, porque você conbece o bebê de 9 meses normal. Normal todo mundo sabe como trocar a fralda. O bebê prematuro é diferente. Tem toda a técnica, todo o jeitinho de trocar a fralda, de limpar. São coisas 
diferentes do bebê normal, do que o bebê prematuro de 7 , 6 de 5 meses [...] (OfA E1).

Uma experiência, porque, no canguru, como a criança foi prematura, está ensinando os cuidados que deve ter com ele (E5). É uma experiência nova, coisa que eu nem sabia, né? Eu não sabia que dava banbo no recém-nascido todo enroladinho com a toalha [...] [risos]. (OfA E4).

Só que, com meu filbo, é tudo diferente, é totalmente diferente pelo fato de ser prematuro. A forma de trocar, de dar banho e também no começo foi um pouquinbo assim, meio complicado, pelo fato de ser do interior... Então senti falta da filha, do esposo e tudo. Só que é uma experiência nova, é muito boa, estou aprendendo bastante. (OfA E3).

As mães, durante a experiência, expressaram medo e culpa pelo nascimento prematuro, mas a enfermaria canguru é uma oportunidade nova para cuidado desse ser prematuro:

Quando o médico falou que ele ia para UTI, aquilo foi um choque para mim e aquele choque amadureceu [mãe] [...] (E12). É uma experiência diferente. É difícil a gente sair da nossa casa e vir pra cá entendeu? É um ambiente novo pra mim, mas é uma experiência maravilhosa! Só da gente estar aqui com nosso filbo, a gente suporta todos esses obstáculos [...] (OfA E2).

\section{Subcategoria 3: Aprendizado de mães de RN prematuro com o Método Canguru}

A mãe começa aprender a cuidar do seu filbo [...] (E11). Aprender e passar carinho e amor para os bebês, que é o que eles precisam, e o calor do corpo da gente, pra eles ganhar o peso e a confiança da pessoa [...] (E1). Para mim, está sendo uma lição de aprendizagem. Estou aprendendo a cuidar, a cuidar dele, que não é um bebê de 9 meses. Ele é pequeno e o cuidado com ele é totalmente diferente de um bebê grande [...] (OfB E1). Aqui estou aprendendo a cuidar de meus bebês [...] (E9). É difícil para todas nós, mas é uma experiência também, a gente aprende a cuidar do bebê. Ela que nasceu pequenininha aí é uma experiência que a gente vai aprendendo, eu que não sabia, é a primeira [...] (OfB E5). A vantagem é que eu vou sair sabendo cuidar deles, que eu não tenho experiência nenbuma, mãe de primeira viagem. E elas ensinam a dar banbo, como aprender a dar mama. (OfB E2). Vou sai daqui já com experiência. (E9).

\section{Subcategoria 4: Fortalecimento do vínculo mãe-filho no Método Canguru}

As mães compreendem a importância do Método Canguru para o fortalecimento do vínculo afetivo, maior proximidade e construção de sentimento de carinho e amor entre elas e o RN prematuro. Além disso, reconhecem a importância desse método como espaço de resgate do tempo, por permear a proximidade com seu filho e acompanhar seu desenvolvimento.

O aconchego de estar perto do seu filho, porque, normalmente, o prematuro não tem idade gestacional, não tem o quilinho certo, o peso certo. Ficam mais na semi. Então, o espaço canguru, pra mim, é o espaço que traz mais a mãe mais próxima de seu filho, o carinho [...] O aconchego da mãe com o filho, é a aproximação da mãe com seu filho. (E11).

Para minha filha foi importante [...] No vínculo que cria ela sente que está presente [...] (E2). Para mim, significa que tem que ter um cuidado a mais com o bebê, porque ela ainda está um pouquinho frágil, ela tem que ficar um pouquinbo comigo mais próximo. (E7). Para mim é bom, porque estou mais perto do meu filbo, estou vendo ele, está ganhando peso. Teve um dia que ele perdeu, mas, pra mim, está sendo bom. As meninas ajudam, o resto é tranquilo. (E10).

\section{Subcategoria 5: Enfermaria canguru como local para a aprendizagem}

Os depoimentos das mães explicitam que a vivência na enfermaria canguru, como espaço de aprendizado contínuo, é também um espaço onde elas fazem novas amizades.

Do dia que eu cheguei aí [na enfermaria] já aprendi muitas coisas. A fazer novas amizades, tipo aí eu já formei uma família. Todo mundo que chega faz um amigo $e$ também a cuidar deles que é prematuro, que eu também não sabia nem pegar. Quando eles chegaram, eu tinha medo de pegar que eles iam quebrar, que eles eram de vidro. Agora não tenho mais medo. (E15).

Então, aqui, para mim, é assim, uma boa oportunidade para as mães, até mesmo de conhecer. Não conhecemos [a nós mesmas] não conhecemos a capacidade que tem de criar uma pessoa, de lidar com outro ser humano, entendeu? Então eu acho muito interessante, uma boa oportunidade para todas as mães. (OfA E1).

As amizades que a gente faz, a maioria mesmo saiu, mas boje em dia eu falo com elas por telefone. E também o fato de estar perto de minha filha [...] o que facilita é a amizade. As médicas também são boas. Tem algumas enfermeiras que ajuda. Tudo depende uma coisa da outra [...] (E2).

Os profissionais de saúde, especialmente enfermeiro, técnico de enfermagem e fisioterapeuta, são facilitadores desse processo de aprendizado e de supervisão. Essas afirmativas são confirmadas nos depoimentos das mães:

Eu aprendi muita coisa que [...] eu não sabia. Também, eu aprendi que, quando a criança se engasga, eu não sabia o que fazer, agora já sei. Aprendi a cuidar dele mais, a dar um banbo, que do meu outro menino, eu nem cuidava direito, não sabia nem dar um banbo. Agora eu já sei. Trocar uma fralda, agora eu já sei, que elas me 
ensinaram. Me ensinaram muita coisa aqui, muita coisa mesmo que eu não sabia, agora já sei [...] (E3).

Acho que ficar aqui é fácil, porque aqui [...] todo mundo é muito gente boa, acolbe muito bem a gente [...] é porque aqui eu vou tá com minha filha 24 boras e todos os funcionários acolhem bem a pessoa, não deixa você se sentir sozinha. Estão sempre tentando fazer o melhor. (E8).

Assim os cuidados, assim também as pessoas são muito companheiras, gosta de ficar com a gente, ensina bastante os cuidados direitos com a criança. É isso! Ensina bastante a gente [...] (E5).

Para mim, o que tá sendo bom é justamente essa vivência com o apoio da equipe de enfermagem, porque, se você tivesse em casa com o bebê tão pequeno e você tivesse alguma dúvida não ia ter com quem tirar [...] (E16).

\section{Discussão}

$\mathrm{Na}$ vivência no Método Canguru, observou-se a importância da estabilidade clínica da criança, o ganho de peso regular, a segurança materna, o interesse e a disponibilidade da mãe em permanecer com a criança o maior tempo desejado e possível. A posição canguru é realizada pelo período que ambos considerarem seguro e agradável $^{(2)}$.

Passada a primeira etapa - em que o RN saiu da UTIN ou UCINco, já iniciou o contato pele a pele e a amamentação precoce já é estimulada, com a participação do pai e da mãe nos cuidados com o RN -, as mães aprendem a identificar as alterações que podem ocorrer com a criança, como pausas respiratórias, mudança de coloração da pele entre outras. Além disso, essa etapa objetiva favorecer não somente a melhora das condições de saúde do RN, ao apresentar novas formas de cuidado, mas também incentivar a formação do vínculo entre a mãe e sua criança $^{(4)}$. Neste estudo, o Método Canguru foi visto como inovador e significativo no aprendizado, para as mães, do cuidado com o RN prematuro, que tem particularidades.

Dessa forma, o Método Canguru amplia a experiência no cuidado do RN após a alta hospitalar. Estudo identifica que, na ocasião do nascimento e logo após, as mães sentem-se inseguras no ato de cuidar de suas crianças e necessitam de auxílio para essa atividade. Elas consideram que, nesse momento, as informações e o apoio fornecido serão importantes na construção desse conhecimento $^{(2)}$. Confirmada neste estudo, a vivência de mães no Método Canguru significa aprendizado e favorece o cuidado e maior proximidade com o RN e, assim, o acompanhamento do seu desenvolvimento.

No Método Canguru, o cuidado com a mãe deve ser praticado de forma mais sistemática e consistente para melhor adesão e confiança. A equipe de saúde deve ser treinada e motivada de forma a aprimorar sua prática nesse método. Considera-se também que a educação continuada com funcionários e a educação em saúde com os pais, além da criação de grupos de apoio entre os participantes da assistência canguru, são elementos decisivos para promover aceitação e segurança das mães canguru ${ }^{(9)}$.

Para isso, os profissionais de saúde devem ajudá-las a fortalecer o vínculo com a criança prematura, principalmente durante o primeiro contato com o filho, já que a maioria demonstra receio da morte iminente, por conta das características frágeis da criança prematura ${ }^{(10)}$. Como visto, o Método Canguru influencia no fortalecimento de vínculos entre mãe e RN prematuro, devido à maior aproximação do binômio.

Nesse sentido, a exemplo do que foi constatado neste estudo, é preciso contar com a equipe de saúde, que tem como uma de suas responsabilidades atuar como facilitadora do processo de educação. Assim, com o intuito de ensejar a adaptação familiar aos cuidados necessários com o RN, essa equipe facilita a aprendizagem em um ambiente propício e acolhedor, com troca de conhecimentos e vivências. A educação em saúde, para as mães, pode ser realizada pela equipe de enfermagem, em particular pelas enfermeiras.

Importante ressaltar que o cuidar é uma ação moral, que tem a finalidade de aliviar, satisfazer, ajudar, confortar e apoiar. Essa ação tem sempre uma conotação que promove e favorece o bem-estar do outro. De forma geral, o processo de cuidar envolve transformação de ambos: o ser cuidado e os cuidadores $^{(11)}$. Além disso, o cuidar concretiza-se com o vínculo ente o cuidador e o cuidado. Significa estar com o outro, no que se refere às relações sociais e especiais da vida, e pode transmitir compaixão, ação e zelo. Nesta concepção, o cuidar está inserido nas relações da existência humana ${ }^{(11)}$. 
Por suas particularidades, o cuidar da criança prematura exige conhecimento e estabelecimento de assistência direcionada às suas necessidades. Abrange cuidar específico durante o internamento e após a alta hospitalar ${ }^{(12)}$. O conhecimento da vivência de mães no Método Canguru, no contexto em que estão inseridas, e dos fatores que influenciam na continuidade do método após a alta hospitalar, são determinantes para ampliar o olhar para o cuidado ao binômio mãe-RN, que podem trazer benefícios para a criança e contribuir para a redução de internações hospitalares e morbimortalidade infantil ${ }^{(5)}$.

Nesse contexto, o contato pele a pele com a mãe é de suma importância, pois propicia à criança relacionar-se com o mundo, abrindo-se para novas descobertas. Esse contato corporal incentiva e promove o aleitamento materno, possibilita melhor adaptação fisiológica e estabilidade térmica do $\mathrm{RN}$, além de promover o vínculo afetivo entre mãe e $\mathrm{RN}^{(13-14)}$. O contato direto da mãe com o filho favorece o cuidado integral, desde as necessidades físicas, emocionais e fisiológicas, pois possibilita empatia, carinho, sensibilidade e segurança para a tríade mãe, filho e equipe de saúde. Além disso, fortalece os vínculos familiares, aumenta a resistência imunológica, com o ganho de peso e o desenvolvimento psicomotor do recém-nascido ${ }^{(15)}$. Este estudo compreende a importância do contato pele a pele da mãe e do $\mathrm{RN}$, por favorecer o desenvolvimento e o ganho de peso da criança.

Para as mães de $\mathrm{RN}$ prematuros, a amamentação apresenta-se como processo complexo. É percebida como relevante e necessária e influencia no crescimento, desenvolvimento saudável, formação de vínculo afetivo entre mãe-filho e recuperação hospitalar. Logo, merece atenção da equipe de enfermagem e da rede de apoio social à mulher, para que o aleitamento materno exclusivo seja concretizado após a alta hospitalar ${ }^{(16)}$.

Nesta pesquisa, observou-se que a vivência contínua na enfermaria do Método Canguru, além de favorecer o vínculo entre mãe e filho, permitiu troca de conhecimento entre essas e os profissionais de saúde, assim como facilitou a construção de vínculo afetivo duradouro, importante para o alcance do objetivo desse método.

Diante da possibilidade de promover segurança básica necessária à construção da vinculação efetiva entre mãe e RN, o Método Canguru permite à mãe criar espaço para a reconstrução rítmica dessa díade, possibilitando o resgate de tempo interrompido entre a mãe e o RN, com o nascimento prematuro ${ }^{(17)}$.

A prática do Método Canguru é uma das melhores formas de ajudar na recuperação dos RN, ao reforçarem a proximidade do filho, a troca de amor e carinho. Tal afirmação aplica-se aos resultados deste estudo, em que mães expressam tais sentimentos e constroem segurança para lidar com as especificidades dessa fase, conforme compartilhado por algumas mães de outro estudo ${ }^{(18)}$.

De modo complementar, a condição da maternagem no interior da prematuridade é algo complexo, pois é atravessada pela vivência de trauma, culpa, medo da perda da criança e percepção de sua fragilidade, que tem, no Método Canguru, a possibilidade de conexão entre mãe e filho ${ }^{(17)}$.

Nesse contexto, a vivência na unidade canguru representa a construção de conhecimentos atrelados às experiências vivenciadas, com destaque para as primíparas que, em sua primeira experiência, deparam-se com um RN prematuro, que necessita de cuidado singular e diferenciado. Assim, o Método Canguru, além de proporcionar maior vínculo entre mãe/RN, familiares e profissionais de saúde, permite também ser espaço de criação e ampliação das relações sociais.

Esse método funciona também como modo de aprendizagem para a continuidade do cuidado no domicílio. Para isso, o acolhimento à mãe e ao pai, durante a permanência hospitalar do RN prematuro ou de baixo peso ao nascer, é necessário e importante e deve ser estendido aos demais familiares que, nessa situação particular e diferente, necessitam de apoio e orientação. Nesse aspecto, o objetivo maior do acolhimento é fazer com que as experiências emocionais que ocorrem nesse período sejam bem entendidas e elaboradas ${ }^{(2)}$. Para isso, o acolhimento deve ocorrer de forma integral, comportando 
a adequação dos cuidados às necessidades de cada família para o cuidado específico do RN. A atuação da equipe de saúde é fundamental para o estabelecimento de relação empática e que transmita segurança e troca de experiências e sentimentos, quando possível.

A atenção de forma adequada, oferecida pela equipe de saúde na enfermaria canguru, possibilita à mãe sua adaptação progressiva às rotinas da unidade e para o cuidado de seu filho com mais segurança. Ademais, permite que, gradualmente, a mãe fique mais próxima, além de possibilitar toques frequentes e cuidado progressivo até o momento em que possa acolhê-lo junto ao seu corpo, na posição canguru ${ }^{(2)}$, o que é corroborado nos depoimentos deste estudo.

O Método Canguru é um modelo de assistência neonatal que oferece benefícios ao recém-nascido prematuro e de baixo peso e à sua família, com destaque para a participação efetiva da mãe e do pai desde o início, favorecendo positivamente o aprendizado para o cuidar da criança no ambiente domiciliar ${ }^{(19)}$. Esse aprendizado foi evidenciado também neste estudo, e ocorreu com base nas orientações das profissionais de saúde, assim como na troca de experiências compartilhadas entre as demais mães que vivenciavam situação semelhante na enfermaria canguru.

Além disso, o Método Canguru contribui para a humanização no serviço de saúde, por unir os pais ao seu filho, sobretudo a mãe. O contato do RN com os pais auxilia na superação da crise gerada pelo nascimento prematuro e pelo longo período de internação, ao promover uma experiência singular e gratificante para a família envolvida ${ }^{(19)}$. Além disso, estudo evidencia que esse procedimento proporciona da mãe com o método, favorece os cuidados da mãe com o bebê de baixo peso ao nascer, reduz a carga de morbimortalidade, proporciona o aumento de ganho de peso, favorece a adesão à amamentação exclusiva e reduz o tempo de hospitalização ${ }^{(20)}$.

O preparo da mãe para o cuidado do $\mathrm{RN}$ prematuro no domicílio deve ocorrer durante toda a internação da criança, quando se procura desenvolver habilidades e a construção de conhecimentos específicos ${ }^{(21)}$. O desenvolvimento de habilidades de cuidado é orientado por profissionais e proporciona confiança e segurança para o cuidado do filho antes mesmo do momento da alta ${ }^{(21)}$. Além disso, ao oferecer essa assistência, fatores contextuais e normas socioculturais precisam ser levados em consideração, pois influenciam na adoção de cuidados pela mãe ${ }^{(9)}$.

Para isso, é fundamental contar com profissionais de saúde capacitados que componham equipe multidisciplinar e atuem junto às mães de crianças prematuras e/ou baixo peso ao nascer. Esses profissionais devem assisti-las desde o primeiro contato com seu filho, estimulando-as a expressar seus sentimentos, com a finalidade de aliviar ansiedades e angústias, notadamente relacionadas à prática da amamentação ${ }^{(22)}$.

No estudo, durante a coleta de informações na enfermaria canguru, foi possível observar, na rotina diária, que as mães adquiriam progressivamente autonomia para cuidar de seu filho ou filha, desde a troca de fralda, realização do banho, administração da dieta por sonda, oferta de leite no copo, posicionamento adequado para amamentação, até cuidados antirrefluxo, que incluem posição adequada da criança para amamentar e arrotar, posição para troca de fralda e para dormir.

Essa autonomia das mães para o cuidado do RN durante a permanência na unidade canguru é relevante, pois elas irão cuidar de seus filhos no domicílio, muitas vezes sem o auxílio de profissional de saúde. Desse modo, é necessário que se sintam seguras para identificar os sinais de alerta e a necessidade de retorno à unidade hospitalar, para acompanhamento e avaliação, afora ter cuidados preventivos, realizar cuidados higiênicos e amamentação de livre demanda. Para isso, precisam contar com rede de apoio familiar que as auxilie nesse processo.

A rede de apoio que a mãe tem para o processo de cuidar/cuidado no domić́lio inclui o suporte oferecido pela família ou outras pessoas que se dispõem a ajudá-la, a organização de serviços que proporcionam assistência ao indi víduo, o amparo social, educativo, espiritual e de saúde $^{(23)}$. É importante que essa rede de apoio 
domiciliar aconteça desde o momento da internação da criança e de sua mãe no alojamento canguru, pois, além de acolhê-la e orientá-la para o cuidado domiciliar, fornece amparo a essa mãe e ao RN durante a internação hospitalar.

O preparo da família para a alta das Unidades Neonatais pode ser considerado um desafio para a equipe de enfermagem. Todavia, não deve constituir momento isolado na alta hospitalar do RN. Ao contrário, a alta deve ser considerada um processo contínuo a ser iniciado desde a entrada na instituição e apoiado em ações que requerem avaliação permanente das demandas do RN e da família ${ }^{(24)}$.

Neste estudo, observou-se incipiência de participação do pai ou outro membro familiar na enfermaria canguru, pois quase sempre eram encontradas apenas as mães no cuidado de seus filhos. Como a presença do pai ou da avó limitava-se ao horário de visita, a posição canguru sempre era realizada pela mãe, exceto na instituição $\mathrm{A}$, onde houve a permanência da irmã da genitora por um período um pouco superior a $24 \mathrm{~h}$ na unidade canguru, em decorrência do afastamento da genitora por problema de saúde (conjuntivite).

Diante dessa contextualização, com relação ao Método Canguru, é necessário criar estratégias para facilitar o entendimento de pais e demais familiares, durante a internação hospitalar do RN, sobre a importância da amamentação, da ordenha do leite, da participação ativa dos pais, desde a Unidade de Terapia Intensiva Neonatal e enfermaria canguru, do envolvimento de todos no cuidado ao $\mathrm{RN}^{(6)}$. Isso, certamente, contribuirá com o aprendizado das mães e influenciará na qualidade dos cuidados ao RN.

Este estudo teve como limitações o local, por ter sido duas instituições públicas de saúde, com perfis diferentes, uma com atendimentos de especialidades médicas variadas e obstetrícia, e a outra uma maternidade, assim como o fato de tratar-se de momento delicado e complexo para a mãe - nascimento, internamento, preocupação e (im)previsibilidade da alta hospitalar. Isso, por sua vez, pode ter influenciado na experiência e nos significados apreendidos das mães de RNs prematuros quanto ao Método Canguru.

\section{Conclusão}

Evidenciou-se que a assistência e os cuidados neonatais associados ao Método Canguru reforçam seu valor para a sobrevida e a redução da morbidade de neonatos. Ao lado disso, as questões individuais que facilitam ou atendem às necessidades singulares de cada mãe são significativas para essa sobrevida e constituem-se em elementos primordiais para sua autodeterminação e autonomia, além de importantes para o alcance da cidadania.

O uso de oficina de reflexão, entrevistas e observação participante para produção dos dados foram adequados e permitiram obter conhecimento sobre o significado da vivência de mães internadas em unidade canguru. Foi possível observar que a vivência contínua na enfermaria do Método Canguru possibilitou a construção de conhecimentos atrelada à ampliação ou aquisição de experiências, principalmente para as primíparas, por se tratar de RN prematuro, que necessita de cuidado singular e diferenciado, somado ao aumento do vínculo entre mãe/RN e demais familiares e profissionais de saúde, permitindo também ser espaço de criação e ampliação das relações sociais.

$\mathrm{Na}$ aprendizagem, fica explícita a importância do preparo das mães para o cuidado ao $\mathrm{RN}$, aspecto que deve ser trabalhado desde a primeira etapa do Método Canguru, que ocorre na UTI neonatal, pois essa mãe, muitas vezes, não irá contar com a ajuda de profissionais no domićlio e necessita de aprendizado contínuo para adquirir experiência e autonomia para a realização desses cuidados.

Neste estudo, foi observado que as mães adquiriam o conhecimento específico para o cuidado com o RN gradativamente. Mais fortalecidas na segunda etapa do Método Canguru, que ocorre na enfermaria canguru, elas adquiriam progressivamente autonomia para cuidar de suas crianças, ao aprenderem a realizar atividades que envolviam desde a troca de fralda à realização do banho, administração da dieta por sonda e pelo corpo, posicionamento adequado para amamentação, cuidados antirrefluxo, que incluem a posição adequada da criança para 
amamentar e arrotar, assim como a posição para a troca de fralda e para dormir. O déficit de participação do pai ou outro membro da família tende a fragilizar os laços afetivos familiares, limitar ou tornar mais difícil a participação desses no apoio à mãe no domicílio, dificultar a adesão ao método e fragilizar o aprendizado.

Por fim, como visto, no Método Canguru é importante a atuação da equipe multidisciplinar, em particular da enfermagem, na orientação, no preparo e no acolhimento da mãe e da família do RN, além da participação da rede de apoio familiar. A equipe de saúde, ao proporcionar ambiente acolhedor, favorece o atendimento às necessidades singulares das envolvidas. Destarte, é fundamental estabelecer esforços, no sentido de considerar as especificidades de cada mãe, RN e família, e reconhecê-los como parceiros no cuidado, conforme os objetivos do Método Canguru.

\section{Colaborações:}

1 - concepção, projeto, análise e interpretação dos dados: Joise Magarão Queiroz Silva e Mariza Silva Almeida;

2 - redação do artigo e revisão crítica relevante do conteúdo intelectual: Joise Magarão Queiroz Silva, Mariza Silva Almeida, Edméia de Almeida Cardoso Coelho, Karla Ferraz dos Anjos, Tyciana Paolilo Borges e Írbia Fernandes de Medeiros;

3 - aprovação final da versão a ser publicada: Joise Magarão Queiroz Silva, Mariza Silva Almeida e Karla Ferraz dos Anjos.

\section{Referências}

1. Vargas Porras C, Villamiar Carvajal B, Ardila Suárez EF. Expectativas de crianza en madres de recién nacidos a término y pretérmino. Rev cuba enferm [Internet]. 2016 jul-set [cited 2019 Oct 10];32(3). Available from: https://pesquisa. bvsalud.org/portal/resource/pt/biblio-960370

2. Brasil. Ministério da Saúde. Atenção Humanizada ao Recém-Nascido de Baixo Peso: Método Mãe Canguru. Manual técnico [Internet]. Brasília (DF); 2017 [cited 2019Jun 12]. Available from: http://www. corensc.gov.br/wp-content/uploads/2017/09/ atencao_humanizada_recem_nascido_canguru.pdf
3. Spehar MC, Seidl EMF. Percepções maternas no método canguru: contato pele a pele, amamentação e autoeficácia. Psicol Estud. 2013 Dec;18(4):647-56. DOI: https://doi.org/10.1590/ S1413-73722013000400007

4. Mendes GVS, Rocha SS, Sales JCS, Araújo OD, Araújo LO. Método Canguru na Unidade de Cuidado Intermediário Neonatal Convencional. Rev Enferm UFPI. 2015 Oct-Dec;4(4):68-74. DOI: https://doi.org/10.26694/reufpi.v4i4.4958

5. Reichert APS, Soares AR, Bezerra ICS, Dias TKC, Guedes ATA, Viera DS. Vivência materna com o Método Canguru no domicílio. Reme - Rev Min Enferm. 2020;24:e-1295. DOI: http://www.dx.doi. org/10.5935/1415-2762.2020002

6. Dantas JM, Leite HC, Querido DL, Esteves APVS, Almeida VS, Haase MMMC, et al. Percepção das mães sobre a aplicabilidade do método canguru. Rev enferm UFPE on line. 2018 Nov;12(11):2944-51. DOI: 10.5205/1981-8963-v12 i11a235196p2944-2951-2018

7. Brasil. Ministério da Saúde. Resolução n. 466, de 12 de dezembro de 2012. Aprova as diretrizes e normas regulamentadoras de pesquisza envolvendo seres humanos [Internet]. Brasília (DF); 2012 [cited 2014 May 23]. Available from: https:// conselho.saude.gov.br/ultimas_noticias/2013/06_ jun_14_publicada_resolucao.html

8. Bardin L. Análise de conteúdo. Edição rev actual. Tradução Luís Antero Reto e Augusto Pinheiro. Lisboa: Edições 70; 2011.

9. Chan GJ, Labar AS, Wall S, Atun R. Kangaroo mother care: a systematic review of barriers and enablers. Bull World Health Organ. 2016;94(2):130-41. DOI: 10.2471/BLT.15.157818

10. Costa R, Heck GMM, Lucca HC, Santos SV. Da incubadora para o colinho: o discurso materno sobre a vivência no método canguru. Rev Enferm Atenção Saúde [Internet]. 2014 Jul-Dec [cited 2019 May 25];3(2):41-53 Available from: http://seer.uftm.edu.br/revistaeletronica/ index.php/enfer/article/view/1019

11. Cestari VRF, Moreira TMM, Pessoa VLMP, Florêncio RS, Silva MRF, Torres RAM. The essence of care in health vulnerability: a Heideggerian construction. Rev Bras Enferm [Internet]. 2017 Oct [cited 2020 Apr 10];70(5):1112-6.. Available from: https://pubmed.ncbi.nlm.nih.gov/28977242/

12. Aires LCP, Santos EKAS, Costa R, Borck M, Custódio ZAO. Seguimento do bebê na atenção básica: interface com a terceira etapa do método 
canguru. Rev Gaúcha Enferm [Internet]. 2015 [cited 2018 Apr 12];36(spe):224-32. Available from: http://www.scielo.br/pdf/rgenf/v36nspe/01026933-rgenf-36-spe-0224.pdf

13. Maldonado MT. Psicologia da gravidez. 16a ed. São Paulo: Saraiva; 2002.

14. Santos LM, Silva JCR, Carvalho ESS, Carneiro AJS, Santana RCB, Fonseca MCC. Vivenciando o contato pele a pele com o recém-nascido no pós-parto como um ato mecânico. Rev Bras Enferm [Internet]. 2014 mar-abr [cited 2015 May 17];67(2):202-7. Available from: https://www.scielo.br/pdf/reben/ v67n2/0034-7167-reben-67-02-0202.pdf

15. Santana JCB, Assis APO, Silva CCD, Quites HFO. Método mãe canguru e suas implicações na assistência: percepção da equipe de enfermagem. Rev Enferm [Internet]. 2013 jan-abr [cited 2014 Oct 10];16(1):34-48. Available from: http://periodicos. pucminas.br/index.php/enfermagemrevista/ article/view/13017\#: :text=O\%20 MMC\%20 favorece $\% 200 \% 20$ processo, de $\% 20$ forma $\% 20$ mais\%20natural\%20poss\%C3\%ADvel.

16. Bezerra MJ, Carvalho ACO, Sampaio KJAJ, Damasceno SS, Oliveira DR, Figueiredo MFER. Percepção de mães de recém-nascidos prematuros hospitalizados acerca da amamentação. Rev baiana enferm. 2017;31(2):e17246. DOI: 10.18471/ rbe.v31i2.17246

17. Souza LP, Souza EV, Gomes GCS, Souto DF, Pereira LB, Pinheiro MAM, et al. Método mãe-canguru: percepção da equipe de enfermagem na promoção à saúde do neonato. Rev Bras Promoção Saúde [Internet]. 2014 jul-set [cited 2015 Jun 15];27(3):374-80. Available from: https://periodicos.unifor.br/RBPS/article/ view/2731

18. Moreira JO, Romagnoli RC, Dias DAS, Moreira CB. Programa Mãe-Canguru e a Relação Mãe-Bebê na Rede Pública de Betim: Pesquisa Qualitativa. Rev Psicol Estudo [Internet]. 2009 jul-set [cited 2014
Jun 14];14(3):475-83. Available from: https://www. scielo.br/pdf/pe/v14n3/v14n3a08

19. Sales IMM, Santos JDM, Rocha SS, Araújo Filho ACA, Carvalho NAR. Sentimentos de mães na unidade canguru e as estratégias de suporte dos profissionais de enfermagem. Rev Cuid [online] 2018 dez;9(3):2413-22. DOI: http://dx.doi.org/10.15649/cuidarte.v9i3.545

20. Conde-Agudelo A, Díaz-Rossello JL. Kangaroo mother care to reduce morbidity and mortality in low birthweight infants. Cochrane Database Syst Rev. 2016 Aug;2016(8):CD002771. DOI: 10.1002/14651858.CD002771.pub4

21. Chiodi LC, Aredes NDA, Scochi CGS, Fonseca LMM. Educação em saúde e a família do bebê prematuro: uma revisão integrativa. Acta paul enferm. 2012;25(6):969-74. DOI: https://doi. org/10.1590/S0103-21002012000600022

22. Osorio SP, Ochoa Marín SC, Semenic S. Preparing for post-discharge care of premature infants: Experiences of parents. Invest Educ Enferm [Internet]. 2017 [cited 2020 May 8]; 35(1):100-8.Available from: http://www.scielo. org.co/scielo.php?script=sci_arttext\&pid= S0120-53072017000100100

23. Silva JR, Thomé CR, Abreu RM. Método Mãe Canguru nos Hospitais / Maternidades Públicas de Salvador e Atuação dos Profissionais da Saúde na segunda etapa do Método. Rev CEFAC [Internet]. 2011 maio-jun [cited 2020 May 10];13(3):522-33. Available from: https://www.scielo.br/scielo.php?pid=S1516$18462011000300016 \&$ script $=$ sci_arttext $\&$ tlng=pt

24. Morais AC, Quirino MD, Almeida MS. O cuidado da criança prematura no domicílio. Acta paul enferm. 2009;22(1):24-30. DOI: https://doi.org/ 10.1590/S0103-21002009000100004

Recebido: 26 de maio de 2020

Aprovado: 3 de agosto de 2020

Publicado: 8 de outubro de 2020

A Revista Baiana de Enfermagem utiliza a Licença Creative Commons - Atribuição-NãoComercial 4.0 Internacional. https://creativecommons.org/licenses/by-nc/4.0/ Este artigo é de acesso aberto distribuído sob os termos da Licença Creative Commons (CC BY-NC). Esta licença permite que outros remixem, adaptem e criem a partir do seu trabalho para fins não comerciais. Embora os novos trabalhos tenham de lhe atribuir o devido crédito e não possam ser usados para fins comerciais, os usuários não têm de licenciar esses trabalhos derivados sob os mesmos termos. 